\title{
Impact of Consanguinity on Fertility and Mortality
}

\author{
Dr. K. Bharathi \\ Assistant Professor, Guru Ghasidas Viswavidyalaya, Bilaspur, Chhattisgarh-495009
}

\begin{abstract}
An attempt is made to find out the parental consanguinity on inbreeding of Khond, a particularly vulnerable tribal group belonging to Visakhapatnam district of Andhra Pradesh. In a cross-sectional study of the tribe, socio-economic characteristics along with demographic data were collected using structured schedule. Further the sample was selected through random sampling method and it was reported that out of 247 numbers of married women, 167 women preferred consanguineous marriages and remaining 80 women preferred non-consanguineous marriages. The mean sex-linked $\overline{\mathbf{F}}_{s}$ value $(0.0728)$ is slightly higher than the mean autosomal $\overline{\mathbf{F}}_{a}$ value (0.0439). All fertility components are higher for consanguineous couples compared to the non-consanguineous couples. The proportion of prenatal deaths was reported to be more among consanguineous unions while postnatal deaths were reported to be more among non-consanguineous unions.
\end{abstract}

\section{Introduction}

Marriage is a component of population change but it has profound influence on fertility and mortality and it is the reason for deferment beyond the time of puberty (Cox, 2008). The age at which a female marries for the first time and enters the reproductive period of life has a great impact on the fertility. Even today the age at marriage is low and pre-pubertal marriages are prevalent among many tribal communities of India. Fertility and mortality are fundamental determinants of population growth in order to understand the changes in the genetic structure of a population. However, to understand human fertility, its variations among different groups and causes of the variations, it is necessary to analyze the mechanisms through which socio-economic variables influence fertility. The genetic variability present in any gene pool in the form of recessive mutations imposes a hereditary burden in population in the form of mortality and morbidity suffered by the homozygotes. This hereditary burden is referred as the genetic load, which has been defined in a number of ways by Muller (1950), Crow (1960), Wallace and Dobzhansky (1959). One approach currently used to estimate the load is from the data provided by consanguineous matings. The assumption in this approach is that deleterious mutations are recessive genes and their presence in the gene pool of a population should be revealed in the reproductive performance of consanguineous matings. As the closely related individuals have a greater chance of carrying identical alleles, the children of consanguineous matings have a greater chance of being homozygous for rare recessive alleles than the children from non-consanguineous matings. The theoretical and methodological problems involved in genetic load studies are many and Sanghvi $(1966,1974)$ questioned the Indian context. However, it is a known fact from several studies that there are reproductive inequalities in the consanguineous and non-consanguineous matings, and it is necessary to test the validity of the above hypothesis in a tribal population practicing inbreeding since many generations.

Fertility is slightly higher in the consanguineous groups than in the non-consanguineous groups due to lower age at marriage among JenuKuruba and KaduKuruba tribes (Mutharayappa, 2000). Biological as well as socio-cultural factors are responsible for the differential fertility and mortality among human populations (Elizabeth 2000; Emma Kerkeni et al. 2007; Mostafizur Rahman et al. 2008). Research studies repeatedly emphasize that biological and socio-cultural variables like age at menarche, age at marriage, type of marriage, economic levels, education (Mamta Murthi et al., 1995) and birth control methods have significant influence on the fertility and mortality of a population (Meerambica et al. 1999; Das and Goswami 2004; Hammami 2005; Al- Kandari 2007; Bosch 2008; Koc 2008). So far no anthropological research work has been reported on Khond tribal group of Andhra Pradesh. Therefore, an attempt has been made to study the effects of parental consanguinity on inbreeding were assessed in terms of the number of pregnancies, live births and surviving children per woman, and total mortality that includes prenatal and postnatal deaths from the time of birth to reproduction.

\section{Material and Methods}

For the present study, the primary data was collected from Visakhapatnam district of Andhra Pradesh which possesses a comparatively higher proportion of Khond tribal population. The currently married women of the age group 13 to $45+$ years were chosen as the respondents. A total of 247 couples from an endogamous group with at least one married woman in the house drawn from 26 villages selected from Chinthapalli, 
Pedabayalu and G.Madugula mandals of Visakhapatnam district were interviewed in the sample survey. A pretested structured schedule was used to retrieve the information on demography by assuming random sampling method and consequently drawing pedigrees of the families. The data was subsequently cross-checked from neighbours, village elders, and as well as from the relatives residing nearby. Besides quantitative data, some qualitative information on fertility preference, norms and practices regarding health and conception were collected through key-informants, group discussions and informal interviews. The data comprised the name of the head of the family, age of wife, husband and children, type of consanguineous relationship between spouses, marital status, income, age at menarche, age at marriage, differentials of fertility, differentials of mortality, measures of fertility and measures of mortality. Demographic data were analysed as per the standard techniques following Barclay (1958). Fertility data was measured by considering average number of conceptions, livebirths and the total number of surviving children. However, mortality was measured by the number of prenatal deaths including abortions, miscarriages and stillbirths, by the number of post-natal deaths including neonatal, infantile, juvenile, child and adolescent deaths.

Wright (1921) defined co-efficient of inbreeding " $F$ " as correlation between uniting gametes, while Malecot (1948) defined as the probability that the homologous genes of uniting gametes are identical by descent. Thus " $F$ " is the probability of autozygosity. The values of co-efficient of inbreeding for various kinds of consanguineous marriages for autosomal $\left(\mathrm{F}_{\mathrm{a}}\right)$ and sex linked $\left(\mathrm{F}_{\mathrm{s}}\right)$ genes are different. It is widely known that consanguineous marriages do not affect the genotype frequencies of sex linked genes in sons, since they possess a single " $X$ " chromosome. However, for computing the coefficient of inbreeding for sex linked genes in a female, only the number of females in a pedigree is considered, leaving any path with two successive males. In the present investigation the following Wright's formula as illustrated by Rao (1978) was used.

$\mathrm{F}_{\mathrm{a}}=\sum \mathrm{C}_{\mathrm{i}} . \mathrm{F}_{\mathrm{ai}} ; \quad \mathrm{F}_{\mathrm{s}}=\sum \mathrm{C}_{\mathrm{i}} . \mathrm{F}_{\mathrm{si}}$

Where $C_{i}$ is the proportion of marriage type and $F_{a i}$ is the inbreeding coefficient for autosomal genes $\left(\mathrm{F}_{\mathrm{si}}\right)$ for sex linked genes.

The pooled data was computed by applying the software SPSS (Statistical Package for Social Sciences - Version 16) to draw final inference.

\section{Results and Discussion}

The dependence of fertility on marriage is clearly very important. The age at which marriage occurs also has a considerable influence on fertility. This influence may operate in several ways such as early marriage provides increased opportunities for producing and rearing children (Cox, 2008). Khond people are endogamous groups who mostly practice consanguineous marriages subsequently resulting in inbreeding. However, there is increase in the frequency of homozygosity which in turn affects the genetic structure of the population and nonconsanguineous marriages encourage outbreeding giving chance to heterozygous condition. The mean age at marriage of the women is reported to be 15.37 years. The total number of pregnancies (118 pregnancies), the number of live births (117 live births) and surviving children (117 surviving children) are reported high among 15-16 years of age at marriage of women. The types of marriage and inbreeding coefficients of the present study are presented in Table 1. Out of 247 married couples, 167 women had practiced consanguineous marriages $(67.61 \%)$ and 80 women had adapted to non-consanguineous $(32.38 \%)$ marriages. The mother's brother's daughter (MBD) type of marriage is predominant that accounted to $(55.46 \%)$ than the father's sister's daughter

Table 1: Distribution of Non-Consanguineous and Consanguineous Marriages and Inbreeding Coefficient among Khond

\begin{tabular}{|l|l|l|l|l|l|l|l|l|l|}
\hline \multirow{2}{*}{ Tribe } & \multirow{2}{*}{$\begin{array}{l}\text { Total } \\
\text { Marriage }\end{array}$} & \multirow{2}{*}{$\begin{array}{l}\text { N/ } \\
(\%)\end{array}$} & $\begin{array}{l}\text { Non- } \\
\text { Consangu } \\
\text { ineous } \\
\text { marriages }\end{array}$ & $\begin{array}{l}\text { Uncle- } \\
\text { niece }\end{array}$ & FSD & MBD & \multicolumn{2}{|c|}{$\begin{array}{l}\text { Total } \\
\text { Consanguineous }\end{array}$} & \multicolumn{2}{|l}{$\begin{array}{l}\text { Inbreeding } \\
\text { Co-efficient }\end{array}$} \\
\hline Khond & 247 & $\begin{array}{c}\mathrm{N} \\
(\%)\end{array}$ & $\begin{array}{c}80 \\
(32.38)\end{array}$ & $\begin{array}{c}7 \\
(2.83)\end{array}$ & $\begin{array}{c}23 \\
(9.31)\end{array}$ & $\begin{array}{c}137 \\
(55.46)\end{array}$ & $\begin{array}{c}167 \\
(67.61)\end{array}$ & 0.0439 & 0.0728 \\
\hline
\end{tabular}

(Figures in parentheses indicate percentages)

$$
\begin{aligned}
& * \overline{\mathrm{F}}_{\mathrm{a}}=\text { Inbreeding Co-efficient for Autosomal genes } \\
& * * \overline{\mathrm{F}}_{\mathrm{S}}=\text { Inbreeding Co-efficient for Sex-linked genes }
\end{aligned}
$$

(FSD) with a frequency of $(9.31 \%)$ and $(2.83 \%)$ of women reported uncle-niece marriages. Further, the mean sex-linked $\left(\overline{\mathbf{F}}_{\mathrm{S}}\right)$ value $(0.0728)$ is higher than the mean autosomal $\left(\overline{\mathbf{F}}_{\mathrm{a}}\right)$ value $(0.0439)$, due to higher proportions of mother's brother's daughter and uncle niece type marriages. The fertility and mortality differentials in relation to consanguineous and non-consanguineous marriages are represented in Table 2. 
Table 2: Differential Fertility of Ever Pregnant Women based on type of Marriage

\begin{tabular}{|c|c|c|c|c|c|c|c|c|}
\hline \multirow{2}{*}{ Tribe } & \multirow{2}{*}{ Types of Marriage } & \multirow{2}{*}{$\mathbf{N}$} & \multicolumn{2}{|c|}{ Conceptions } & \multicolumn{2}{|c|}{ Live births } & \multicolumn{2}{|c|}{ Surviving children } \\
\hline & & & $\mathrm{N}$ & $\overline{\bar{Z}}$ & $\mathrm{~N}$ & $\overline{\mathcal{Z}}$ & $\mathrm{N}$ & $\overline{\bar{X}}$ \\
\hline \multirow{3}{*}{ Khond } & $\begin{array}{l}\text { Non- } \\
\text { Consanguineous }\end{array}$ & 73 & 234 & 3.20 & 225 & 3.08 & 176 & 2.41 \\
\hline & Consanguineous & 157 & 542 & 3.45 & 518 & 3.29 & 428 & 2.72 \\
\hline & Total & $* 230$ & 776 & 3.37 & $\begin{array}{c}743 \\
(95.25)\end{array}$ & 3.23 & $\begin{array}{c}604 \\
(77.33)\end{array}$ & 2.62 \\
\hline
\end{tabular}

*Excluding the infertile or never pregnant women (17 women)

(Figures in parenthesis indicate percentage)

Among the study sample, the overall live births reported $95.25 \%$ live births whereas the proportion of surviving children reported to be $77.33 \%$. However, the trend of mean live births and number of surviving children among consanguineous matings are higher (3.29) and (2.72) when compared to the mean values for non-consanguineous matings (3.29) and (2.41) respectively. Consanguineous marriages show slightly higher fertility rates when compared to non-consanguineous marriages.

Table 3 shows that the proportion of prenatal death rates is higher (11\%) among the women at 15-16 years of marriage age and the proportion of postnatal deaths of children account to $48.84 \%$ among the women at

Table 3: Frequency distribution of Age at Marriage in relation to Fertility and Mortality

\begin{tabular}{|lccccc|}
\hline Ageat Marriage & \multicolumn{4}{c|}{ Fertility and Mortality } \\
\cline { 2 - 6 } & $\begin{array}{c}\text { Number of } \\
\text { Pregnancies }\end{array}$ & $\begin{array}{c}\text { Number of Live } \\
\text { Births }\end{array}$ & $\begin{array}{c}\text { Total Surviving } \\
\text { Prenatal deaths } \\
(\%)\end{array}$ & $\begin{array}{c}\text { Postnatal deaths } \\
(\%)\end{array}$ \\
\hline$<12$ & 12 & 12 & 12 & $1(8.33)$ & $5(41.67)$ \\
\hline $13-14$ & 50 & 49 & 47 & $5(10.0)$ & $20(40.82)$ \\
\hline $15-16$ & 118 & 117 & 117 & $13(11.0)$ & $41(35.04)$ \\
\hline $17-18$ & 43 & 43 & 42 & $3(6.98)$ & $21(48.84)$ \\
\hline $19+$ & 7 & 7 & 6 & 0 & $2(28.57)$ \\
\hline Total & 230 & 228 & 224 & $22(9.56)$ & $89(39.03)$ \\
\hline
\end{tabular}

(Figures in parenthesis indicate percentage)

17-18 years of age. However, these rates substantially differ when total sample is taken into consideration, wherein early age at marriage of women reported higher prenatal deaths reporting to $9.56 \%$ and postnatal deaths recorded at $39.03 \%$ for Khond women.

Table 4: Distribution of Mortality type among Consanguineous and Non-Consanguineous marriages

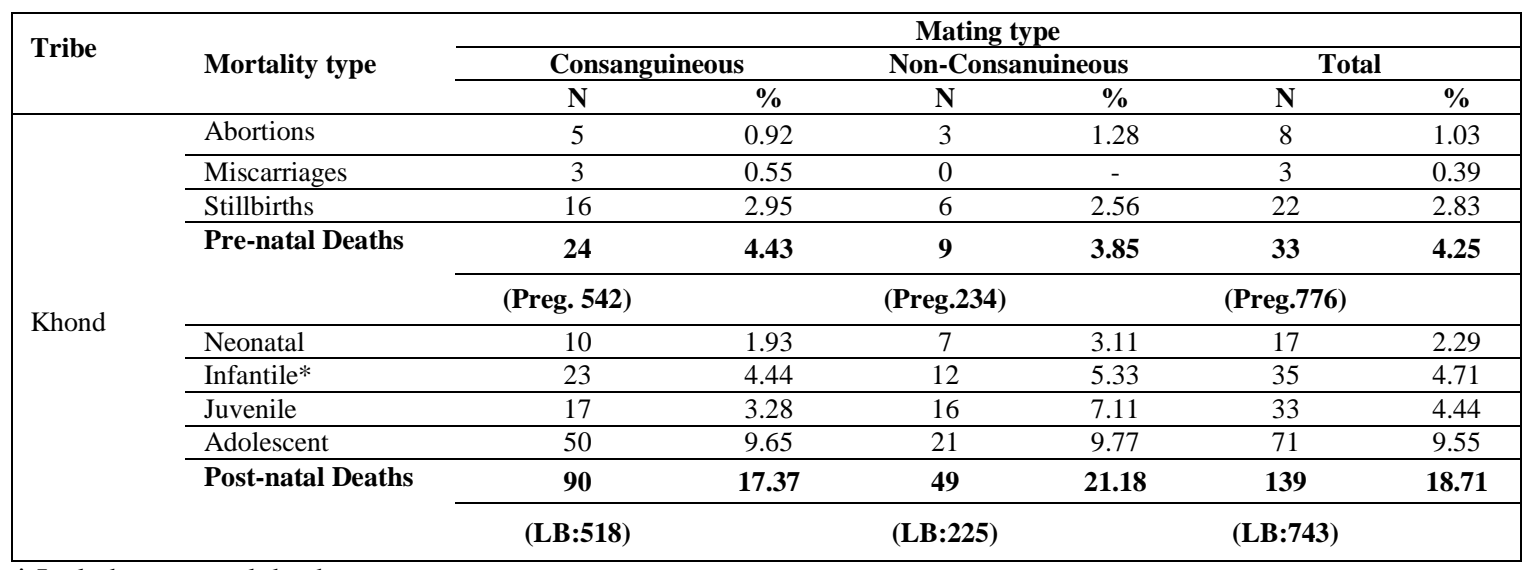

* Includes neonatal deaths

It is observed from the Table 4, that the proportion of prenatal deaths is higher among the consanguineous mating (4.43\%) than the non-consanguineous mating (3.85\%) accounting to higher still births in consanguineous marriages. However, a reverse trend is observed in the case of postnatal deaths where women of consanguineous union reported lower postnatal deaths $(17.37 \%)$ than non-consanguineous unions which reported $21.18 \%$ postnatal deaths. 


\section{Conclusion}

Khond population exhibited slightly higher fertility rates among consanguineous matings than the nonconsanguineous matings. Similarly prenatal mortality rates reported to be higher in consanguineous unions than non-consanguineous. However, Khond women reported higher postnatal deaths among non-consanguineous than consanguineous unions. Khond population treat children as economic assets to their family and women are encouraged to produce more number of children resulting in higher fertility. Mortality is reported to be higher which can be attributed meager attention and poor economic conditions that enable them to substantiate their health needs especially resulting in child mortality. However, improving socio-economic conditions, rigorous awareness, outreach and proper implementation of medical facilities besides educating the mother about maternal care and health can improve the health status of the tribes.

\section{Acknowledgements}

The data was collected with the help of financial assistance extended from University Grants Commission, New Delhi for the Major Research Project is gratefully acknowledged. The author wishes heartfelt thanks to University Grants Commission. The author also wishes thanks to all the Khond tribal people who have constantly co-operated in learning to know about their culture, health and demographic aspects. The author acknowledges the publisher for their constant cooperation in the article processing.

\section{References}

[1]. Al-Kandari YY. 2007 Fertility and its relationship with socio-cultural factors in Kuwaiti society. East Mediterranean Health Journal, 13(6), 1364-71.

[2]. Barclay, G.W. 1958. Techniques of population analysis. John Wiley \& Sons, Inc., New York.

[3]. Bosch Alinda M, Frans J Willekens, Baqui Abdullah H, Jeroen KS, Van Ginneken, Inge Hutter. 2008 Association between Age at menarche and early life nutritional status in rural Bangladesh. Journal of Biosocial Science, 40, 223-237.

[4]. Cox, Peter, R. 2008 Demography, Cambridge University Press, Cambridge, New York.

[5]. Crow, J.F.1960 Mutation and Selective balance as factors influencing population fitness. In: Molecular Genetics and Human Disease. L.I.Gardner (ed)., Charles C.Thomas, Springfield, Illinois.

[6]. Das,Rekha, Goswami,Mayuri. 2004 Fertility Performance of a Tea Working Population of Dibrugarh District, Assam. Journal of Human Ecology, 16(2), 119-123.

[7]. Elizabeth A.M, Saraswathy K.N, Sachdeva M.P, Rewa Chaudhary, Kalla A.K,.2000 Demographic profile of Thoti: A primitive tribal population of Andhra Pradesh. Anthropologist, 2, 119-117.

[8]. Emma Kerkeni, Kamel Monastiri, BesmaSeket, Mohmed Neji Ghuediche, Hassen Ben Cheikh,. 2007 Interplay of socio-economic factors, consanguinity, fertility and offspring mortality in Monastir, Tnisia. Croat Med. Journal, 48 (5), 701-707.

[9]. Hammami A, Chalbi N Ben, Abdallah M, Elgazzeh M 2005. Effects of Consanguinity and Social factors on Mortality and Fertility in Mauritania. Tunis Med, 83(4), 221-226.

[10]. Koc 2008. Prevalence and Socio-Demographic correlates of consanguineous marriages in Turkey. Journal of Biosocial Science, 40(1), 137-48.

[11]. Malecot, G.1948. Les Mathematiques de L'Heredite. Masson. Paris. Cited from 'Human Biology of the Chenchus of Andhra Pradesh', A Demo-Morpho-Genetic Study', by Sirajuddin, S.M.

[12]. Mamta Murthi, Anne-Catherine Guio, Jean Dre`ze. 1995 Mortality, Fertility and Gender bias in India: A district level analysis, Population Council, Vol.21 (4), 745-782.

[13]. Meerambica Mahapatro, Sachadeva MP, Kalla AK 1999. Demographic profile of Bhattara, Tribal population of Nowrangpur district, Orissa. Anthropologist, 2:133-137.

[14]. Mostafizar Rahman, Ismai Tareque, Tanveer Mahmood 2008. Effects of socio-demographic factors on fertility in Bangladesh: Cross-tabulation analysis. Social Sciences, 3(6), 436-441.

[15]. Muller, H.J. 1950. "Our load of mutations". Am.J.Hum.Genet., 2: 111-76.

[16]. Muthurayappa, R.2000Tribal Fertility, Mortality and Health Care Practices, Mittal Publications, New Delhi.

[17]. Rao, P.S.S. 1978. Consanguinity and Inbreeding in India. Paper presented at the international symposium on population structure and human variation, Bombay, Dec 18-21.

[18]. Sanghvi, L.D.1966. "Inbreeding in India”. Eugen. Quat., 13:291-301.

[19]. Sanghvi, L.D. 1974. The genetic consequences of inbreeding and outbreeding in the role of natural selection in human evolution. A BurgWartenstein Symposium. No.63.

[20]. Wallace, B. and T. Dobzhansky. 1959. Radiation, genes and man. Henry Holt, New York.

[21]. Wright, S. (1921). Systems of mating. Genetics 6: 111-178. 